\title{
VR in Education: Ergonomic Features and Cybersickness
}

\author{
Olha Pinchuk ${ }^{1(\bowtie)}$, Oleksandr Burov ${ }^{1}$, Svitlana Ahadzhanova ${ }^{2}$, \\ Victoriya Logvinenko ${ }^{2}$, Yana Dolgikh ${ }^{2}$, Tetyana Kharchenko ${ }^{2}$, \\ Olena Hlazunova ${ }^{3}$, and Andrii Shabalin ${ }^{4}$ \\ ${ }^{1}$ Institute of Information Technologies and Learning Tools, Ukraine, \\ 9 M. Berlyns'koho Street, 04060 Kyiv, Ukraine \\ opinchukl00@gmail.com, ayb@iitlt.gov.ua \\ ${ }^{2}$ Sumy National Agrarian University, Sumy, Ukraine \\ prof_lavrov@hotmail.com \\ ${ }^{3}$ National University of Life and Environmental Sciences of Ukraine, \\ Kyiv, Ukraine \\ o-glazunova@nubip.edu.uae \\ ${ }^{4}$ Scientific Research Institute of Intellectual Property, Kyiv, Ukraine \\ ab96@ukr.net
}

\begin{abstract}
This paper describes theory (systemic structural model) of learning activity in the virtual reality, as well as demonstrates (on experimental data) in psychophysiological regulation of the cognitive activity in VR. Understanding of these changes can be used for learning improvement using VR environment regards the interrelationship between the structure and self-regulation of learning activity, avoiding potential cybersickness.
\end{abstract}

Keywords: Ergonomics $\cdot$ Virtual reality $\cdot$ Cybersickness $\cdot$ Education

\section{Introduction}

It is recognized that virtual reality (VR) is a type of the synthetic learning/training environment [1]. VR gadgets can be autonomous or network-connected, and human work and life acquire new features in e-World [2]. As a result, new ergonomic questions in e-World need more specific ergonomic tasks to be solved [3]. At the same time, it is necessary to take into account that human cognitive opportunities can vary from day to day depending on his/her functional state and fitness-for-work, that needs in mutual adaptation of a human and the system, including a learning system [4]. Such changes can influence human ability to adapt in a particular work/learning environment, to perceive and to conceive new information, use it, get knowledge and skills, and prevent its inefficiency [5], including cloud technologies [6].

This challenge can be especially acute for VR in education, because of number of questions that are waiting for answer up to date:

- the main types of training/education guidance and in what way can immersive technologies help with the different learning styles; 
- which industries are seeing the biggest adoption of immersive training;

- challenges and limitations of VR or AR/MR into a training system;

- what can immersive technology not be good for;

- what can be the broader benefits of XR in the short- and long-term perspective;

- what can be "dark" side of VR/AR/XR in education (first of all - cybersickness, individual response to the new type of activity);

- what is psychophysiological response of a human to focused cognitive work with digital units/gadgets?

Professional development of todays' teachers should foresee this side of teaching, first of all, in digital learning environment [5], accounting systemic-structural concept to understand peculiar properties of learning activity [6] and as a systemic activity, in general [7], including nowadays' requirement of learning in lifespan [8]. Special attention is paid to electronic devices in education [9] and influence of VR tools for this [10].

Purpose. To study cognitive ergonomic reasons of ineffective cognitive activity in digital environment or emergence of cybersickness in it.

\section{Method}

The cybersickness has been modeling in experimental study of cognitive activity with measuring of its psychophysiological response to a human focused (with high motivation and without external disturbances) cognitive test performance with and without time pressure, as in research [11]. In addition, the technique included measurement of electropuncture diagnostics' indices (EPD) by Nakatani (24 regular points and 3 stress' points), as well measurement of lipid metabolism using sweat collection before and after the test session for each subject [12].

Subjects: 28 males of 18-40 year old.

The experiments differed by the test (permutation of random non-repeating digits from 0 to 9 in ascending order) workload: training E1 (60 min); E5 - free rate ("«autopace"), and E6 - fixed rate calculated as average by results of the appropriate test performance in E1.

As indices of physiological "cost" of activity and the human state we registered a heart rate HR and blood pressure (systolic ADs, diastolic ADd) by means of the cardiomonitor "Solveig". The indices HR, ADs and ADd we registered during 10 min prior to the tests beginning (index " 0 ") and $10 \mathrm{~min}$ after finishing (relaxation), as well as every 20 min during the test activity [11]. Analysis of stress (time and focused cognitive activity) has been carried out for two experiments by physiological indices.

\section{Discussion of Results}

Many researchers studying advantages and draw-backs of VR pay attention to the related sickness of body movement and posture that are inhabit for normal human activity. But at the same time, the human brain can suffer from intensive immersed 
activity much more, because its work is supported by physiological regulation, and its overloading can lead to unnecessary stress. Repetitive stress, even at the acceptable level, can lead to the cumulative effect, loss of a human psychophysiological resistance. The human activity in VR is an immersive activity, by its nature. Therefore, a work in digital environment (with digital tools) can be a model of the controlled human performance to study some external and internal influences.

In our research, we compared two conditions of the subject's cognitive task performance: with and without time pressure, with high motivation.

It was revealed that tension of physiological regulation (myocardial tension index after R. Baevsky) is higher in conditions of time pressure (Fig. 1), having fluctuation over time of the experiment $(3 \mathrm{~h})$. In other words, it can be a marker of the relative stable performance. At the same time, a new question has aroused: what is the "cost" of such a stable regulation of myocardium?

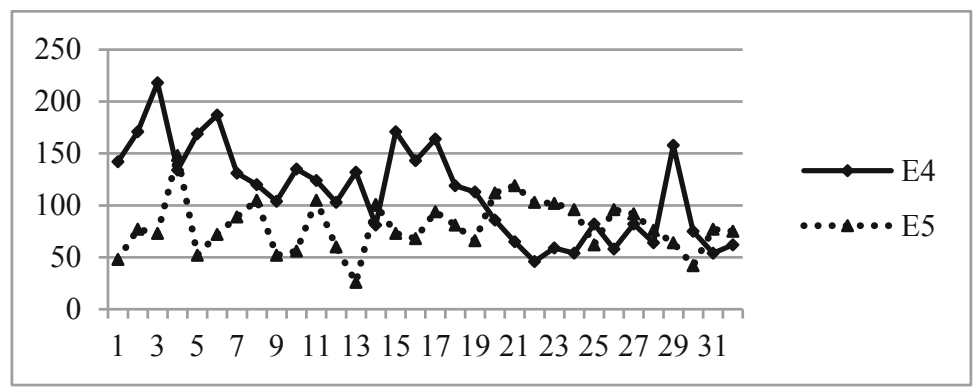

Fig. 1. An example of the myocardial tension index changes over the time of experiments (one subject). Note: E4, E5 - see chapter "Method"

Analysis of the stress level by EDP indicators demonstrated its high changes from the beginning to the end of each experiment: values in three acupuncture points could increase up to two times, especially in the experiments with time pressure, but in different directions in all subjects. This means that focused cognitive activity even of medium level is accompanied by some stress response from the physiological regulation.

The data from the analysis of the lipid metabolism have shown adverse changes in low-density lipid levels, what can be preliminary sickness indicator in conditions of regular repetitive workload of such a nature.

We believe that VR is the brightest manifestation of the immersive environment for education/training, and has some specific features in comparison with more traditional digital devices including computers. A learner is considered as a type of operator (in ergonomic context), namely operator-researcher, and it is reasonable to analyze the psychophysiological mechanisms of the cognitive activity, when the object of activity (mental) is not external in relation to the human, but internal one. The model of the cognitive work developed by the authors can be specified for the case of VR, where activation of the sensory inputs (Fig. 2, red-line loop) happen not so from the outer environment, as from the Virtual Act Program without activating the Act Program 
mechanism. This model can explain, why such regulation can deplete and imbalance the body: Act Program works in coordination with the Act Acceptor and Substratum needed for the normal life and activity. But lack of the signals from the Act Program cannot activate the general feedback from activity, only simulating it at the neurological level.

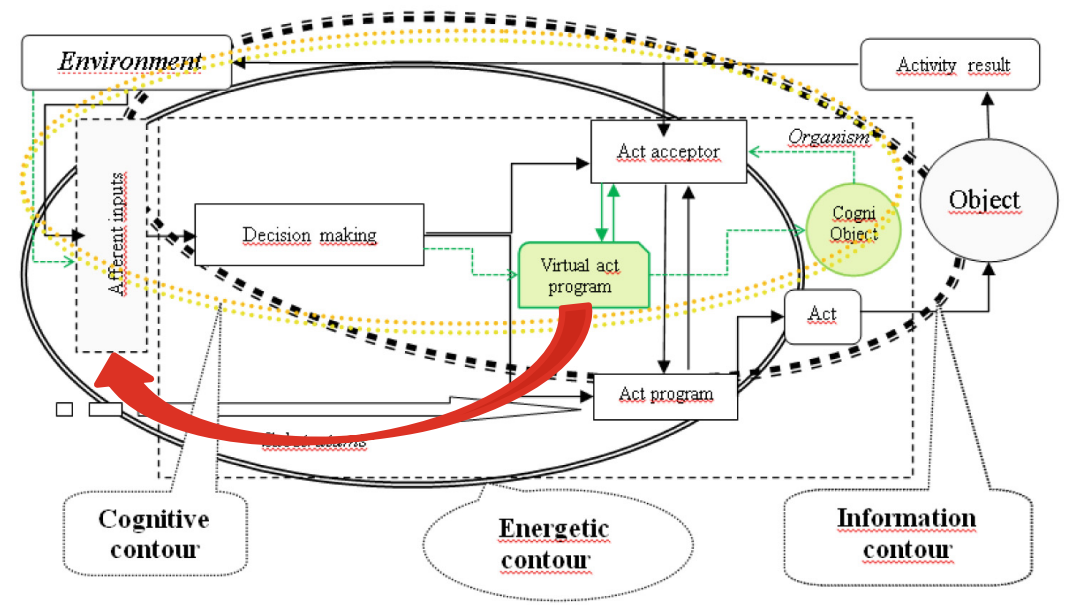

Fig. 2. Theoretical scheme of the functional system of learning activity in VR, where regulation was divided into two contours - information and energetic ones. The third (cognitive) contour is associated with the "internal" activity (modified from [13])

The analysis of data known and received in our study allows considering some specific features of VR:

- If in the real world the user interacts with the digital world through a "window" (computers, tablets and mobile gadgets) observing what is happening "from the outside", "immersion" is the condition in which the user loses awareness of the facts actually occurring in an artificial world.

- If in the real world the user involves almost only vision (other sensors are not involved or they supply non-observational information), in "immersion", the user experiences the virtual world with involved his/her senses and is able to interact with the virtual environment.

- Sensory useful (target) load approaches $100 \%$ and requires $100 \%$ attention and concentration, regardless of the significance of the task. Sensory "hunger" (with monotonous operator activity) can be replaced by sensory exhaustion.

- According to our experimental and theoretical results, authors proposed to focus next study on:

- assessment of the physiological "cost" of the use of immersive environment for adults (military) and students (high school children and university students as future military), 
- assessment and prediction of a human ability to work in VR without negative consequences, optimization of work in VR using HF/E findings and adaptive optimization.

We have to make some notes in relation cybersickness and simulators: cognitive test performance in our research is not the same as simulators as such $[14,15]$, because it was real cognitive work, but with some simplifications. We believe our results could be applied for VR objects with some specifications and accounting new VR tools [f.e., 16].

\section{Conclusion}

This paper describes theory (systemic structural model) of learning activity in the virtual reality, as well as demonstrates (on experimental data) in psychophysiological regulation of the cognitive activity in VR. Understanding of these changes can be used for learning improvement using VR environment regards the interrelationship between the structure and self-regulation of learning activity, avoiding potential cybersickness.

Acknowledgments. This research has been supported by the Institute of Information Technologies of the National Academy of Pedagogic Science.

\section{References}

1. Pinchuk, O., Lyvynova, S., Burov, O.: Synthetic educational environment - a footpace to new education. Informacijni tekhnologhiji i zasoby navchannja: elektronne naukove fakhove vydannja. 60(4), 28-45 (2017)

2. Burov, O.: Virtual life and activity: new challenges for human factors/ergonomics. In: Symposium Beyond Time and Space STO-MP-HFM-231, STO NATO 2014, pp. 8-1-8-8 (2014)

3. Burov O.: Human factors/ergonomics in eWorld: methodology, techniques and applications. In: Karwowski, W. et al. (eds.): AHFE 2019. AISC, vol. 971, pp. $459-466$ (2019). https:// doi.org/10.1007/978-3-030-20135-7_26

4. Lavrov, E., Lavrova, O.: Intelligent adaptation method for human-machine interaction in modular E-learning systems. In: Proceedings of the 15th International Conference on ICT in Education, Research and Industrial Applications. Integration, Harmonization and Knowledge Transfer. Volume II: Workshops, Kherson, Ukraine, 12-15 June 2019, pp. 1000-1010 (2019)

5. Mulder, L.J.M., Van Roon, A., Veldman, H., Laumann, K., Burov, A., Quispel, L., Hoogeboom, P.J.: How to use cardiovascular state changes in adaptive automation. In: Hockey, G.R.J., Gaillard, A.W.K., Burov, O. (eds.) Operator Functional State. The Assessment and Prediction of Human Performance Degradation in Complex Tasks. NATO Science Series, pp. 260-272. IOS Press, Amsterdam (2004) 
6. Lytvynova, S., Melnyk, O.: Professional development of teachers using cloud services during non-formal education. In: Proceedings of the 12th International Conference on ICT in Education, Research and Industrial Applications. Integration, Harmonization and Knowledge Transfer ICTERI 2016, Kyiv, Ukraine, 21-24 June 2016, vol 1614, pp. 648-655 (2016). CEUR-WS.org. http://ceur-ws.org/Vol-1614/paper_51.pdf

7. Bedny, G.Z., Karwowski, W.: A systemic-structural activity approach to the design of human-computer interaction tasks. Int. J. Hum.-Comput. Interact. 16(2), 235-260 (2003)

8. Burov, O.: Life-long learning: individual abilities versus environment and means. In: Proceedings of the 12th International Conference Harmonization and Knowledge Transfer ICTERI 2016, Kyiv, Ukraine, 21-24 June 2016, vol. 1614, pp. 608-619 (2016). CEURWS.org. http://ceur-ws.org/Vol-1614/paper_86.pdf

9. Morze, N.V., Glazunova, O.G.: Design of electronic learning courses for IT students considering the dominant learning style. In: International Conference on Information and Communication Technologies in Education, Research, and Industrial Applications, pp. 261273. Springer, Cham (2014)

10. LaViola Jr., J.J.: A discussion of cybersickness in virtual environments. ACM SIGCHI Bull. 32, 47-56 (2000). https://doi.org/10.1145/333329.333344. CiteSeerX 10.1.1.544.8306

11. Burov, O., Tsarik, O.: Educational workload and its psychophysiological impact on student organism. Work. 41(Suppl. 1), 896-899 (2012)

12. Varus, V.I. et al.: Method of determining resistance of military personnel: pat. 17500 MPK, Ukraine GO1N33/50. 200606000 (2006). Appl. 31.05.06; publ. 15.09.06, Bul. 9

13. Pinchuk O., Burov O., Lytvynova, S.: Learning as a systemic activity. In: Karwowski, W., Ahram, T., Nazir, S. (eds.) Advances in Human Factors in Training, Education, and Learning Sciences. AHFE 2019. Advances in Intelligent Systems and Computing 2019, vol 963, pp. 335-342. Springer, Cham (2019). https://doi.org/10.1007/978-3-030-20135-7_33

14. Stanney, K.M., Kennedy, R.S., Drexler, J.M.: Cybersickness is not simulator sickness. Proc. Hum. Factors Ergon. Soc. Ann. Meeting 41(2), 1138-1142 (1997). https://doi.org/10.1177/ 107118139704100292

15. Kolasinski, E.M.: Simulator sickness in virtual environments (ARI 1027). U.S. Army Research Institute for the Behavioral and Social Sciences. www.dtic.mil. Accessed 22 July 2017

16. Kemeny, A., George, P., Mérienne, F., Colombet, F.: New VR navigation techniques to reduce cybersickness. Electron. Imaging 2017(3), 48-53 (2017). https://doi.org/10.2352/ issn.2470-1173.2017.3.ervr-097 